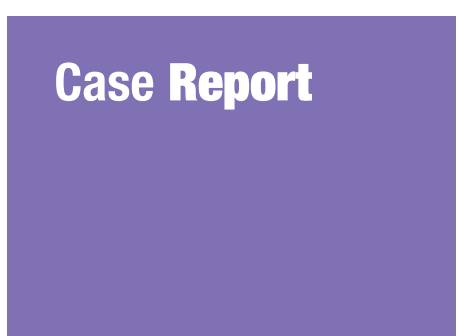

Submitted: 7 Mar 2016 Accepted: 2 Jun 2016 Online: 24 Feb 2017

\section{Bilateral Mirror Image Cervical Neurofibroma in an Adult with Neurofibromatosis Type 1}

\author{
Sharad PANDEY', Kulwant Singh ${ }^{1}$, Vivek SHARMA ${ }^{1}$, Mohammed \\ TABISH KHAN ${ }^{1}$, Amrita GHOSH ${ }^{2}$, Deepa SANTHOSH ${ }^{2}$
}

Department of Neuro Surgery, Sir Sunder Lal Hospital, IMS (Institute of Medical Science), BHU(Banaras Hindu University), Varanasi, Uttar Pradesh-221005, India

2 Department of Pathology, Sir Sunder Lal Hospital, IMS BHU, Varanasi, Uttar Pradesh-221005, India

To cite this article: Pandey S, Singh K, Sharma V, Tabish Khan M, Ghosh A, Santhosh D. Bilateral mirror image cervical neurofibroma in an adult with neurofibromatosis type 1. Malays J Med Sci. 2017;24(1):117-120. https:// doi.org/10.21315/mjms2017.24.1.13

To link to this article: https://doi.org/10.21315/mjms2017.24.1.13

\begin{abstract}
Neurofibromatosis type 1 (NF1) is an autosomal dominant disorder characterised by various phenotypic features like hyperpigmented spots, neurofibromas, Lisch nodules, skeletal abnormalities and tendency to develop neoplasms. Only few cases of Non-Familial Spinal Neurofibromatosis-1 (Non-FSNF1) have been described in literature with tumors involving the spinal roots at every level being even rarer. We reported an interesting case of bilateral symmetrical cervical neurofibroma with multiple spinal neurofibromas appearing as mirror image on CT, associated with non familial NF-1 as a rare presentation in a 25 -year-old adult male.
\end{abstract}

Keywords: neurofibromatosis type 1, bilateral, cervical, spinal nerve root

\section{Introduction}

Neurofibromatosis type 1 (NF1) is an autosomal dominant disorder characterised by various phenotypic features like hyperpigmented spots, neurofibromas, Lisch nodules, skeletal abnormalities and tendency to develop neoplasms (1). NF1 associated with wide, symmetrically distributed spinal neurofibromas are not common. Furthermore, occurrence is still rarer in members of the same family in familial spinal NF1 (FSNF1) (2). In FSNF1 multiple, extensive, bilateral spinal root neurofibromas occur leading to signs and symptoms of progressive, segmentally distributed nerve sheath neuropathy in absence of spinal cord symptoms. Very few cases of Non-FSNF1 have been described in literature so far. Most of the published series so far comprised of segmental involvement of the spinal roots by the tumour affecting patients of various age groups $(3,4,5)$.

We are presenting a case of bilateral symmetrical cervical neurofibroma appearing as mirror image with multilevel spinal neurofibromas, associated with non familial NF-1 which is rare presentation in a 25 year-old adult male.

\section{Case Presentation}

A 25-year-old adult male presented in the neurosurgery of Outpatient Department (OPD) with complaint of progressive weakness of all the four limbs associated with tingling and numbness since last 4-5 months. He also complained of decreased grip in both hands and difficulty in walking since one month. No history of bladder and bowel dysfunction was present. On physical examination multiple small subcutaneous nodule, cafe-au-lait macules were present over the whole body. There was no family history of similar clinical features. On examination, sensation was decreased below $\mathrm{C}_{5}$ level in UL/LL (upper and lower limbs), power in both UL $3 / 5$ and both LL 4/5. Tone was 
increased in both the lower limbs; DTRs (Deep tendon reflexes) were exaggerated.

Magnetic resonance imaging (MRI) demonstrated well defined bilateral symmetric mass lesion measuring approximately $1.2 \mathrm{~cm}$ $\times 0.8 \mathrm{~cm}$, isointense on $\mathrm{T} 1$ and hyperintense on T2-weighted images, involving bilateral neural foraminas of $\mathrm{C}_{5}-\mathrm{C} 6$ levels and causing its widening (Figure $1 \mathrm{a}-\mathrm{c}$ ). Multiple lesions with similar characteristics were also noted involving lumbar and sacral levels, showing relatively homogenous post contrast enhancement. Routine laboratory investigations were within normal limits. Surgical intervention was planned under general anaesthesia. The patient was placed in prone position using pin fixation. Under microscopic magnification, laminectomy was performed at C6 level. The duramater was then opened and the tumour was dissected bilaterally, and the affected roots were localised. After careful separation of mass lesion from surrounding structures and sectioning of the fibres entering the mass, the tumour was removed almost completely and sent for histopathological examination (HPE). The duramater was closed in waterproof manner and the wound was closed in anatomic layers. HPE confirmed it to be Neurofibroma (Figure 2). Postoperative period was however uneventful and patient was discharged on 10th post-operative day. On follow-up evaluation, patient showed neurological improvement.

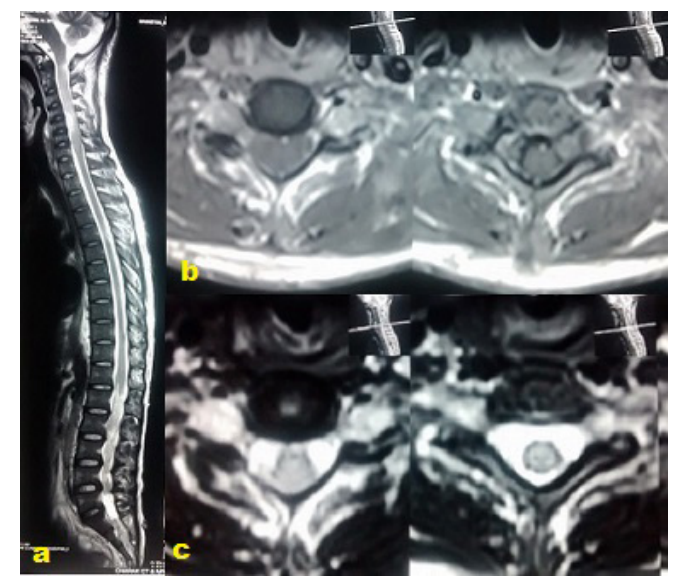

Figure 1. (a) MRI showing T2 weighted mid saggital image having multiple varying sized hyperintense lesions involving cervical, thoracic and lumbosacral levels, with the largest one at $\mathrm{C}_{5}-$ C6 level. (b, c) Axial section of cervical spine showing T1 weighted isointense image and T2 weighted hyperintense image of bilateral intra spinal mass lesion with bilateral neural foraminas widening

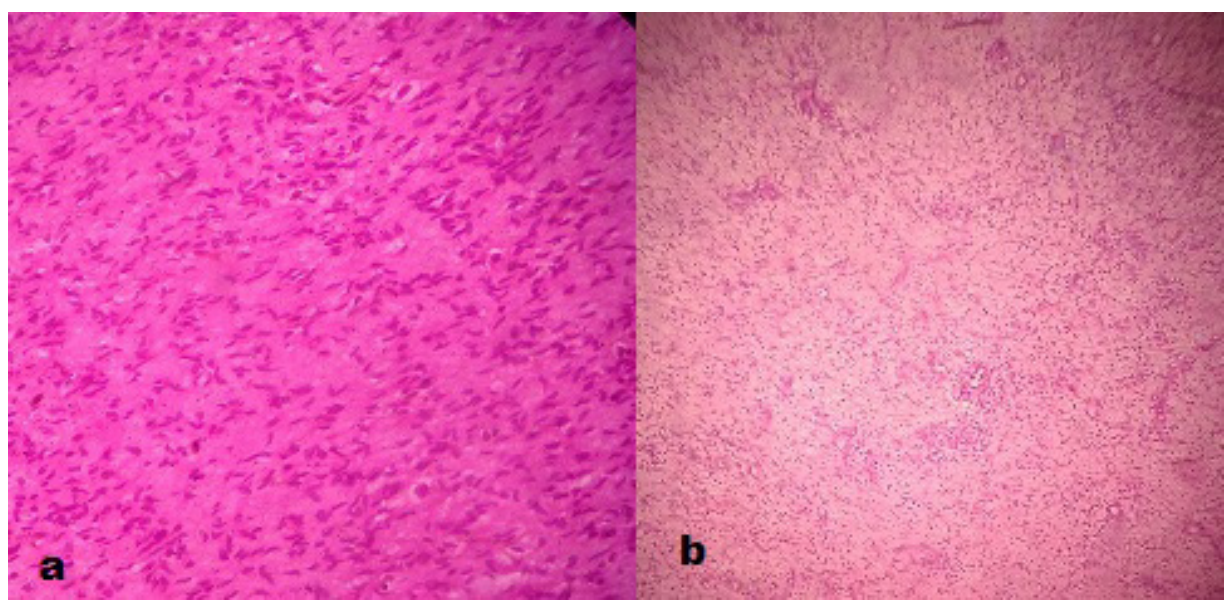

Figure 2. (a) Microphotograph showing spindle shaped neural cells with loose myxoid matrix (H \& E, 100X). (b) Spindle shaped cells with ill defined eosinophilic cytoplasm and tapering, wavy buckled nuclei of neural cells (H \& E, 200X) 
Case Report | Bilateral mirror image cervical neurofibroma

\section{Discussion}

Spinal tumours occur in approximately $40 \%$ of patients with $\mathrm{NF}_{1}$ (6), which are mostly isolated and most often diagnosed as neurofibromas. Especially in paediatric and adolescence population not more than $2 \%$ develop clinical symptoms. However, one of the variants i.e. plexiform neurofibromas usually presents with symptoms due to large size and site (7). During infancy, adolescence and early adult life asymptomatic plexiform lesions should be under regular monitoring annually (8). In the present case, tumours affecting bilateral multiple spinal levels was present and was categorised as non familial form of NF1. Such a presentation is not common in clinical practice. Bilateral tumour involvement was seen in similar series published on bilateral neurofibromas involving spinal nerve from cervical segment to the cauda equina (9). More frequent involvement is of the thoracic and lumbosacral levels compared to the cervical spinal region (9). Very few in number , but similar cases having lesions with symmetrical involvement and homogeneous appearance are reported in literature by Biondetti et al and Bass et al in cases of paraspinal plexiform neurofibromas $(10,11)$.

Due to their anatomical relationship to the vertebral column, neural structures (spinal cord and its nerve roots) and major blood vessels, operating neurofibromas with paraspinal extension is a surgical challenge. Cherqui et al achieved total tumour resection in $78.6 \%$ of cases with neurofibromas (12). Role of microsurgical techniques in identification and if possible, preserving non-involved roots is important (13). Infiltration into multiple adjacent nerves and/ or entire nerve plexus bilaterally makes tumour removal difficult. It becomes more difficult in areas like neck, thorax and pelvis due to adjacent important blood vessels and visceral organs. The current lack of literature on FSNF1 and Non-FSNF1 involving multiple spinal nerves is responsible for the limited knowledge in deciding the most favourable treatment plan and results.

With surgical intervention, spinal neurofibroma causing neurological symptoms usually result in good post-operative functional outcomes. Although chances of recurrence exist with familial form of NF-1 and in cases with subtotal removal but both show good or stable prognosis.

\section{Conflict of Interest}

None

\section{Authors' Contributions}

Conception and design: SP

Analysis and interpretation of the data: SP

Drafting of the article: SP, KS, VS, MTK

Critical revision of the article for important intellectual content: $\mathrm{KS}$

Final approval of the article: VS

Provision of study materials or patients: VS

Administrative, technical, or logistic support: KS

Collection and assembly of data: SP, AG, DS

\section{Correspondence}

Dr Sharad Pandey

MS (Baba Farid University of Health Sciences), MCh (Banaras Hindu University)

Previously affiliated with:

Rajindra Hospital, Government Medical College, Patiala, Punjab

Current affiliation:

Department of Neuro Surgery,

Sir Sunder Lal Hospital, IMS ,BHU,

Varanasi, Uttar Pradesh-221005, India.

Tel: 9454939067

E-mail: drsharad23@yahoo.com

\section{References}

1. National Institute of Health consensus Development Conference Neurofibromatosis: conference statement. Arch Neurol. 1988;45:575578. https://dx.doi.org/10.1001/archneur.1988. 00520290115023

2. Pascual-Castroviejo I, Pascual-Pascual SI, Velazquez-Fragua R, Botella P, Viaño J. Familial spinal neurofibromatosis. Neuropediatrics. 2007;38:105-108. https://dx.doi.org/10.1055/ s-2007-985136

3. Schorry EK, Cawford AH, Egelhoff JC, Lovell AM, Saal HM. Thoracic tumors in children with neurofibromatosis-1. Am $J$ Med Genet. 1997;74:533-537. https://dx.doi.org/10.1002/ (SICI)1096-8628(19970919)74:5<533::AIDAJMG16>3.0.CO;2-D 
4. Leonard JR, Ferner RE, Thomas N, Gutmann DH. Cervical cord compression from plexiform neurofibromas in neurofibromatosis-1. J Neurol Neurosurg Psychiatry. 2007;78:1404-1406. https://dx.doi.org/10.1136/jnnp.2007.121509

5. Tonsgard JH, Kwak SM, Short MP, Dachman AH. CT imaging in adults with neurofibromatosis-1. Frequent asymptomatic plexiform lesions. Neurology. 1998;50:1755-1760. https://dx.doi. org/10.1212/WNL.50.6.1755

6. Upadhyaya M, Spurlock G, Kluwe L, Chuzhanova $\mathrm{N}$, Bennett E, Thomas $\mathrm{N}$, et al. The spectrum of somatic and germline $\mathrm{NF} 1$ mutations in NF1 patients with spinal neurofibromas. Neurogenetics. 2009;10:251-263. https://dx.doi. org/10.1007/s10048-009-0178-o

7. Pollack IF, Colak A, Fitz C, Wiener E, Moreland M, Mulvihill JJ. Surgical management of spinal cord compression from plexiform neurofibromas in patients with neurofibromatosis 1. Neurosurgery. 1998;43:248-256. https://dx.doi. org/10.1097/00006123-199808000-00038

8. Tonsgard JH, Kwak SM, Short MP, Dachman AH. CT imaging in adults with neurofibromatosis-1. Frequent asymptomatic plexiform lesions. Neurology. 1998;50:1755-1760. https://dx.doi. org/10.1212/WNL.50.6.1755
9. Pascual-Castroviejo I, Pascual-Pascual SI, Viaño J, Velazquez-Fragua R, López-Gutierrez JC. Bilateral spinal neurofibromas in patients with neurofibromatosis 1. Brain Dev. 2012 Aug;34(7):563-569. https://dx.doi.org/10.1016/ j.braindev.2011.09.011

10. Biondetti PR, Vigo M, Fiore D, Faveri DD, Ravasini R, Benedetti L. CT appearance of generalized von Recklinghausen neurofibromatosis. $J$ Comput Assist Tomogr. 1983;7:866-869. https://dx.doi.org/10.1097/ oooo4728-198310000-00021

11. Bass JC, Korobkin M, Francis IR, Ellis JH, Cohan RH. Retroperitoneal plexiform neurofibromas: CT findings. AJR Am $J$ Roentgenol. 1994;163:617-620. https://dx.doi.org/10.2214/ ajr.163.3.8079855

12. Cherqui A, Kim DH, Kim SH, Park HK, Kline DG. Surgical approaches toparaspinal nerve sheath tumors. Neurosurg Focus. 2007;22:E9. https:// dx.doi.org/10.3171/foc.2007.22.6.10

13. Pollack IF, Colak A, Fitz C, Wiener E, Moreland M, Mulvihill JJ. Surgical management of spinal cord compression from plexiform neurofibromas in patients with neurofibromatosis 1. Neurosurgery. 1998;43:248-256. https://dx.doi. org/10.1097/00006123-199808000-00038 